\title{
Added Metformin to Systematic Neoadjuvant Chemotherapy in Breast Cancer Patients: Randomized Study from Egypt
}

\author{
SOHA AHMED, M.D., MBA ${ }^{\mathbf{1}}$; AHMED SAID, M.Sc. ${ }^{\mathbf{1}}$; ANWAR A. ELSHENAWY, M.D. ${ }^{\mathbf{2}}$; \\ DINA M. MORSI, M.Sc. ${ }^{3}$; MOHAMED ABDEEN, M.D. ${ }^{\mathbf{4}}$ and MOHAMED ABDELRAHMAN, M.D. ${ }^{4}$ \\ The Department of Clinical Oncology \& Nuclear Medicine, Faculty of Medicine, Aswan ${ }^{1} \&$ Cairo ${ }^{4}$ University, Egypt, \\ General Surgery Department ${ }^{2}$ and Clinical Pharmacy Department, Faculty of Medicine, Aswan University, Egypt
}

\begin{abstract}
Background: Rational of the neoadjuvant chemotherapy can significantly decrease the size and stage of tumor for breast carcinoma. Studies have demonstrated that there is a greater long-term outcome in patients who reach pathological complete response (pCR) following neoadjuvant therapy. Metformin, a biguanide agent, is used as first-line therapy for the treatment of type II Diabetes. The studies reported that diabetic patients with metformin-administered breast cancer and neoadjuvant chemotherapy had a higher pCR rate than diabetics without Metformin.
\end{abstract}

Aim of Study: To assess the efficacy of incorporating Metformin to standard neoadjuvant chemotherapy in breast cancer patients to increase the rate of pathological complete response (pCR).

Patients and Methods: From 1/7/2016 to 1/9/2019, a total of 50 patients were enrolled in the study. Breast cancer patients were equally randomized to receive either standard neoadjuvant AC-Paclitaxel or a similar regimen plus Metformin 500mg twice daily until the time of surgery. For reaction \& toxicity, patients were evaluated.

Results: Concerning all clinical-pathological variables \& biological subtypes, there was no statistically significant difference between both arms. Complete clinical remissions were achieved in 19 patients $(76 \%)$ and 15 patients $(60 \%)$ respectively for the investigated group and standard group ( $p$-value 0.4$)$. In the investigated group, 19 patients $(76 \%)$ were referred to have modified radical mastectomy (MRM) and 6 patients $(24 \%)$ were referred to have complete breast surgical resection (CBS), while in the standard group, 23 patients $(92 \%)$ were referred to MRM and 2 patients $(8 \%)$ were referred to CBS. There was no statistically significant difference between the two types of surgery in the two groups ( $p$-value 0.247 ). The primary endpoint was the $\mathrm{pCR}$ rate in the axilla and breast post operatively. Statistical analysis showed certain trend toward higher rate of pCR with the addition of Metforminin the investigated group compared to the standard group ( $p$-value: 0.08$)$. Uni-variate analysis showed significant correlation with pCR in the 2 groups as regard ER and HER-2/neu positivity, ( $p$-value 0.004$)$

Correspondence to: Dr. Soha Ahmed, The Department of Clinical Oncology \& Nuclear Medicine, Faculty of Medicine, Aswan University, Egypt
The Median DFS at 2 years in our study was $93.25 \%$. Kaplan-Meier survival curves' analysis showed no significant difference between both groups with a DFS of $91.25 \%$ in the investigated group arm, and $96.25 \%$ in the standard group.

Conclusion: The addition of metformin to neoadjuvant chemotherapy has a nearby significant impact on pathological complete response (PCR)in female patients with advanced breast cancer with no significant increased toxicity. Further studiesare recommended to highlight the effect of adding metformin to standard neoadjuvant chemotherapy in ER and/or HER2 positive breast cancer patients.

Key Words: Breast cancer-Neo-adjuvant-Metformin Pathological complete response.

\section{Introduction}

BREAST cancer is one of the largest contributors to the oncology burden in the world. It is the most prevalent disease in women and the leading cause of mortality due to cancer [1]. In Egypt, breast cancer accounts for $(15.4 \%)$ of all cases of cancer, while it is the most prevalent form of cancer in women $(38.8 \%)$ of all cases of female cancer and this percentage rises with the application of national screening program [2].

Neoadjuvant chemotherapy for breast cancer is the standard of care for inoperable non metastatic disease $[3,4]$, Today, also in localized surgically respectable diseases it has been increasingly advocated $[\mathbf{5 , 6 , 7 ]}$. In addition, neoadjuvant chemotherapy offers individualized prognostic results, allows for alterations in adjuvant therapy with weak response to preoperative therapy, [8] and gives the opportunity of achieving pathological complete remission (pCR) which has a very favorable outcomes as endpoint for better outcome in clinical trials [9] Recognize that by supplying tissue samples before and after therapy, it acts as afast and effective medium for evaluating the in vivo reaction of tumors to novel treatments [10]. 
Metformin, because of its strong safety profile, low cardiac mortality and low cost, is the choice of the biguanides family [11]. It's the most widely prescribed oral hypoglycemic drug in type 2 diabetes mellitus (DM) [12,13] . Population-based evidence has emerged since 2005 that metformin has an anti-tumor effect [14].

Many studiesconfirmed this anti-neoplastic effect, have been published, aiming to address the most affected tumor types, and the most benefited groups of patients $[15,16,17]$. Multiple pre-clinical experiments have been conducted to investigate its mechanisms of action [18,19,20]. Metformin is thought to have a direct (insulin independent) effect, and an indirect (insulin dependent) effect [21]. Metformin reduces plasma glucose and insulin levels by inhibiting hepatic gluconeogenesis, and increasing glucose uptake by muscles, preventing insulin resistance, and decreasing obesity, which promote tumor growth [22]. The direct (insulin independent) effect of Metformin is by activation of adenosine-monophosphate kinase (AMPK) via affection of complex I in mitochondrial respiratory chain causing cellular energy stress. Activated AMPK reduces signaling of mammalian target of rapamycin (mTOR), which in turn results in decreased protein synthesis, and tumor growth [23].

The accumulated experience with metformin as anti-diabetic drug, along with its known few manageable side effects; enabled us to speed up clinical trials on its anti-neoplastic activity directly to phase II trials without the need to assess its toxicity \& tolerability by phase I trials.

\section{Aim of study:}

This is a phase II randomized study aimed at evaluating whether metformin use, when added to standard neoadjuvant chemotherapy, would be associated with increase in the $\mathrm{pCR}$ rate in breast cancer patients. The primary endpoint of this randomized study is to determine the efficacy of incorporating metformin to standard neoadjuvant chemotherapy in patients with breast cancer to increase the pCR rate. The secondary endpoint is to address the effect of incorporating metformin to neoadjuvant chemotherapy on clinical response, method of surgery, and toxicity. We have also aimed to find whether the addition of metformin to neoadjuvant chemotherapy has any effect on DFS.

\section{Patients and Methods}

This is a randomized controlled phase II study which conducted at the Clinical Oncology Depart- ment of the Aswan University in the period between July 2016 and Sept. 2019. Fifty patients were included in the study equally weighted into 2 groups (standard group: The patients will receive standard neoadjuvant AC-Paclitaxel until the time of surgery and investigated group: Where the patients will receive similar regimen plus Metformin $500 \mathrm{mg}$ twice daily until the time of surgery who have received neoadjuvant chemotherapy for invasive breast cancer, histology confirmed by tissue core biopsy. Patients were required to have $>3 \mathrm{~cm}$ operable, histologically confirmed, carcinoma of the breast. Other eligibility criteria included: World Health Organization (WHO) performance status $0-1$; adequate bone marrow (white blood cell count $>3.0 \times 10^{9} / \mathrm{L}$ and platelet count $>150 \times 10^{9} / \mathrm{L}$ ), liver function (bilirubin and transaminases $<1.5$ times the upper limit of normal and renal function (creatinine $<1.5 \mathrm{X}$ upper limit of normal), no evidence of metastatic disease, and age $<70$ years with informed written consent. Patients were excluded from the study if they had active cardiac disease (LVEF <50\%), significant arrhythmia, any serious medical or psychiatric condition, or withdrew their consent at any time for any reason. Pregnant or lactating women, or patients who had other malignancy (excluding carcinoma in situ of the cervix and basal cell carcinoma of the skin) or previous breast cancer were also excluded.

\section{Pretreatment evaluation:}

Pretreatment evaluation included histological diagnosis of invasive breast cancer by core needle biopsy, clinical history and physical examination including bi-dimensional measurement of the primary tumor, breast mammogram and ultrasound, full peripheral blood count, plasma urea and electrolytes, serum liver function tests, performance status assessment according to WHO, chest X-ray and electrocardiograph (ECG). Baseline metastatic workup included computerized tomography (CT) of the chest $\&$ Abdomen in addition to Tc99m bone scan.

\section{Treatment regimen:}

Patients wererandomized using closed envelope method in a ratio of 1:1 to receive neo-adjuvant therapy with either: Standard group regimen, four cycles AC (Adriamycin $60 \mathrm{mg} / \mathrm{m}^{2}$, Cyclophosphamide $600 \mathrm{mg} / \mathrm{m}^{2}$ at 3 weeks interval) followed by 12 weeks paclitaxel single agent $80 \mathrm{mg} / \mathrm{m}^{2}$ (standard arm) or Investigated group: Same regimen (4 X $\mathrm{AC}+12 \mathrm{X}$ paclitaxel) plus Metformin 500mg twice/daytill the time of surgery. Trastuzumab was given for all Her $2 u+v e$ cases at a loading dose of 
$8 \mathrm{mg} / \mathrm{kg}$ with the $1^{\text {st }}$ cycle of Paclitaxel \& then at a maintenance dose of $6 \mathrm{mg} / \mathrm{kg}$ at 3 weeks interval during the rest of neo-adjuvant therapy and for a total duration of 1 year. Antiemetic treatment consisted of granisetron and dexamethasone prior to chemotherapy followed by 3 days of domperidone and dexamethasone after chemotherapy.

\section{Follow-up during treatment:}

Patients were treated on an outpatient basis. A full blood countand a biochemical profile were performed on day 1 of each cycle. If the neutrophil count $<1.5 \times 10 / 1$ on day 1 , treatment was delayed for 1 week or until recovery and treatment was given at the full dose.Patients were assessed for toxicity after each course of treatment according to standard WHO criteria 33, and was managed according to blood count cancer guidelines 34 .

\section{Assessment of response:}

A clinical bi-dimensional tumor measurement was performed at each cycle and again 3 weeks after the last course. An ultrasound measurement was carried out after 4 cycles of AC \& prior to surgery. Using both clinical examination \& ultra sound examination, clinical response was evaluated according to standard WHO criteria where complete response (CR) is disappearance of any measurable disease by radiology and clinical examination, partial response (PR) is $50 \%$ or more decrease of tumor size and stable disease is less than $50 \%$ decrease to less than $25 \%$ increase in tumor size ,while progression is more than $25 \%$ increase in tumor size 33 . All patients were offered surgery after completion of neoadjuvant therapy. Breast conserving or mastectomy surgery and axillary node resection were performed based on the clinical response and surgical assessment. Pathologic complete response was defined as the absence of any residual invasive cancer cells in the breast tissue or lymph nodes with the permission of presence of insitu component (ypT0/is ypN0) as proposed by FDA in 201235 .

\section{Survival analysis:}

Disease free survival (DFS) interval was the time between the date of starting randomization and the date of the disease recurrence, the last follow-up or date of death. One-sided log-rank of Kaplan-Meier survival estimates was used for statistical analysis of disease free survival, while the unpaired $t$-test and one-way ANOVA test were used in the univariate analysis of the variables that affect Pcr in both arms.

\section{Results}

\section{Patient characteristics:}

The median age of the investigated group was 50 years, ranged from (31-65 years) while the median age in standard group was 42 years, ranged from (24-65 years), with no statistically significant difference between the two groups $(p=0.31)$. It's worth while mentioning that there is no statistically significant difference between both groups regarding other clinical, pathological variables and biologic subtype as illustrated in Table (1).

\section{Clinical and radiological response:}

All patients in the 2 groups were evaluated clinically after the end of chemotherapy. No patients developed clinical progression or stable disease. The total clinical staging remission post neoadjuvant chemotherapy for both groups was $76 \%$ and $60 \%$ for investigated group and standard group, respectively ( $p$-value 0.393$)$. The clinical staging remission achievedfor the primary breast mass was and for regional lymph nodes are illustrated in Table (2). Regarding radiological response, all patients in the study were evaluated radiologically by breast ultrasound and mammography after the end of chemotherapy to detect any residual suspicious breast mass or residual suspicious lymph nodes. All patients achieved either complete remission or regressive disease. No patients developed radiological progressive disease or stable disease as illustrated in Table (2).

Surgical intervention post neoadjuvant chemotherapy:

As shown in Table (3), all patients were submitted to either modified radical mastectomy (MRM) or conservative breast surgery (CBS). In theinvestigated group, 19 patients $(76 \%)$ were submitted to MRM while 6 patients (24\%) were submitted to CBS, while in the standard group, 23 patients (92\%) were submitted to MRM while 2 patients $(8 \%)$ were submitted to CBS. There was no statistically significant difference between the two groups regarding types of surgery ( $p$-value $0.247)$.

\section{Pathological response:}

The primary endpoint was the rate of pCR in breast and axilla. In the investigated group, 15/25 patients $(60 \%)$ had a pCR versus $9 / 25$ patients (36\%) in the standard group as illustrated in Table (4) Statistical analysis showed a trend toward higher rate of $\mathrm{pCR}$ with the addition of metformin but $p$-value was insignificant ( $p$-value: 0.08 ). 


\section{Correlation between PCR and different criteria:}

The Uni-variant analysis test showed significant correlation with pCR in both randomized groups as regard ER positivity and HER-2/neu positivity while no significant correlation with other variables as illustrated in Table (5).

\section{Toxicity:}

Both treated groups in our study were well tolerated to treatment. The most frequently occurring toxicities were nausea, vomiting, \& diarrhea, peripheral neuropathy, neutropenia, anemia, and thrombocytopenia. Most toxicities were of grades 1 and 2. Many ofthem were possibly related to chemotherapy component of treatment. Grade >3 3 were peripheral neuropathy in 4 patients in Investigated group \& 3 patients in standard group, neutropenia $3 \& 2$ patients respectively and vomiting in only one patient in the investigated group; however, none was statistically significant with a $p$-value of $0.35,0.923$, and 0.518 respectively. Details of toxicities are given in Tables $(6,7)$.

\section{Survival analysis:}

The Median DFS at 2 years in our study was $93.25 \%$. Kaplan-Meier survival curves' analysis showed no significant difference between both groups with a DFS of $91.25 \%$ in the investigated group arm, and $96.25 \%$ in the standard group as illustrated in Table (8).

Table (1): Clinico-pathologic characters of both groups.

\begin{tabular}{|c|c|c|c|c|c|c|}
\hline & & \multicolumn{2}{|c|}{ Investigated group } & \multicolumn{2}{|c|}{ Standard group } & \multirow{2}{*}{$p$-value } \\
\hline & & Count & $\%$ & Count & $\%$ & \\
\hline \multicolumn{7}{|l|}{ Section A } \\
\hline \multirow[t]{2}{*}{ Laterality } & Lt breast & 15 & 60.00 & 14 & 56.00 & 0.744 \\
\hline & Rt breast & 10 & 40.00 & 11 & 44.00 & \\
\hline \multirow[t]{6}{*}{ Site of disease } & LOQ & 2 & 8.00 & 3 & 12.00 & 0.916 \\
\hline & Retro areolar & 11 & 44.00 & 9 & 36.00 & \\
\hline & UIQ & 3 & 12.00 & 2 & 8.00 & \\
\hline & UOQ & 6 & 24.00 & 9 & 36.00 & \\
\hline & LIQ & 2 & 8.00 & 1 & 4.00 & \\
\hline & Axilla & 1 & 4.00 & 1 & 4.00 & \\
\hline \multicolumn{7}{|l|}{ Section B } \\
\hline \multicolumn{7}{|l|}{ TN staging } \\
\hline \multirow[t]{3}{*}{$\mathrm{T}$} & $\mathrm{T} 2$ & 1 & 4 & 1 & 4 & 1.000 \\
\hline & $\mathrm{T} 3$ & 15 & 60.00 & 14 & 60.00 & \\
\hline & $\mathrm{T} 4$ & 9 & 36.00 & 10 & 40.00 & \\
\hline \multirow[t]{2}{*}{$\mathrm{N}$} & $\mathrm{N} 1$ & 12 & 48.00 & 11 & 44.00 & 0.777 \\
\hline & $\mathrm{N} 2$ & 13 & 52.00 & 14 & 56.00 & \\
\hline \multicolumn{7}{|l|}{ Section C } \\
\hline \multirow[t]{2}{*}{ Clinical staging group } & IIIA & 16 & 64.00 & 15 & 60.00 & 0.771 \\
\hline & III B & 9 & 36.00 & 10 & 40.00 & \\
\hline \multirow{2}{*}{$\begin{array}{l}\text { Section D } \\
\text { Pathology }\end{array}$} & IDCa & 22 & 88.00 & 21 & 84.00 & \\
\hline & ILCa & 1 & 4.00 & 3 & 12.00 & \\
\hline \multirow{3}{*}{$\begin{array}{l}\text { Section E } \\
\text { ER }\end{array}$} & Mixed IDCa and ILCa & 2 & 8.00 & 1 & 4.00 & \\
\hline & Negative & 9 & 36.00 & 10 & 40.00 & \\
\hline & Positive & 16 & 64.00 & 15 & 60.00 & \\
\hline \multirow[t]{2}{*}{ PR } & Negative & 8 & 32.00 & 10 & 40.00 & \\
\hline & Positive & 17 & 68.00 & 15 & 60.00 & \\
\hline \multirow[t]{2}{*}{ HER-2/neu } & Negative & 10 & 40.00 & 12 & 48.00 & \\
\hline & Positive & 15 & 60.00 & 13 & 52.00 & \\
\hline \multicolumn{7}{|l|}{ Section $\mathbf{F}$} \\
\hline \multicolumn{7}{|l|}{ Subtype } \\
\hline \multicolumn{2}{|l|}{ Luminal A } & 1 & 4 & 4 & 16 & \\
\hline \multicolumn{2}{|c|}{ Luminal B-like HER-2 negative } & 7 & 28 & 4 & 16 & \\
\hline \multicolumn{2}{|c|}{ Luminal B-like HER-2 positive } & 10 & 40 & 8 & 32 & \\
\hline \multicolumn{2}{|l|}{ HER-2 overexpression } & 5 & 20 & 5 & 20 & \\
\hline \multicolumn{2}{|l|}{ TNBC } & 2 & 8 & 4 & 16 & \\
\hline
\end{tabular}


Table (2): Clinical and radiological Response among both groups.

\begin{tabular}{|c|c|c|c|c|c|c|}
\hline & & \multicolumn{2}{|c|}{ Test group } & \multicolumn{2}{|c|}{ Standard group } & \multirow{2}{*}{$p$-value } \\
\hline & & Count & $\%$ & Count & $\%$ & \\
\hline $\begin{array}{l}\text { Clinical assessment: } \\
\text { T stage }\end{array}$ & $\begin{array}{l}\text { T0 } \\
\text { T1 } \\
\text { T2 }\end{array}$ & $\begin{array}{l}19 \\
4 \\
2\end{array}$ & $\begin{array}{l}76.00 \\
16.00 \\
8.00\end{array}$ & $\begin{array}{l}15 \\
8 \\
2\end{array}$ & $\begin{array}{l}60.00 \\
32.00 \\
8.00\end{array}$ & 0.393 \\
\hline LN Stage & $\begin{array}{l}\text { N0 } \\
\text { N1 } \\
\text { N2 }\end{array}$ & $\begin{array}{l}23 \\
2 \\
0\end{array}$ & $\begin{array}{l}92.00 \\
8.00 \\
0.00\end{array}$ & $\begin{array}{l}22 \\
3 \\
0\end{array}$ & $\begin{array}{l}88.00 \\
12.00 \\
0.00\end{array}$ & 0.343 \\
\hline $\begin{array}{l}\text { Radiological assessment: } \\
\text { Residual breast mass }\end{array}$ & $\begin{array}{l}\text { No } \\
\text { Yes }\end{array}$ & $\begin{array}{l}15 \\
10\end{array}$ & $\begin{array}{l}60.00 \\
40.00\end{array}$ & $\begin{array}{l}9 \\
16\end{array}$ & $\begin{array}{l}36.00 \\
64.00\end{array}$ & 0.156 \\
\hline Residual LN & $\begin{array}{l}\text { No } \\
\text { Yes }\end{array}$ & $\begin{array}{l}23 \\
2\end{array}$ & $\begin{array}{l}92.00 \\
8.00\end{array}$ & $\begin{array}{l}20 \\
5\end{array}$ & $\begin{array}{l}80.00 \\
20.00\end{array}$ & 0.417 \\
\hline
\end{tabular}

Table (3): Type of surgery.

\begin{tabular}{cccccccc}
\hline & \multicolumn{3}{c}{ Investigated group } & \multicolumn{2}{l}{ Standard group } & \\
& Count & $\%$ & & Count & $\%$ & & -value \\
\hline Surgery: & & & & & \\
MRM & 19 & 76.00 & & 23 & 92.00 & 0.247 \\
CBS & 6 & 24.00 & & 2 & 8.00 & \\
\hline
\end{tabular}

Table (4): Pathological Response assessment among both groups.

\begin{tabular}{ccclllll}
\hline & \multicolumn{2}{c}{ Investigated } & & \multicolumn{2}{c}{ Standard } & \\
\cline { 2 - 3 } & Count & $\%$ & & Count & $\%$ & \\
& -value & \\
\hline$p C R:$ & & & & & \\
Yes & 15 & 60.00 & & 9 & 36.00 & 0.08 \\
No & 10 & 40.00 & & 16 & 64.00 & \\
\hline
\end{tabular}

Table (5): Uni-variant analysis of factors affecting pCR.

\begin{tabular}{|c|c|c|c|c|}
\hline Criteria & & $\begin{array}{c}\text { PCR in } \\
\text { Investigated group }\end{array}$ & $\begin{array}{c}\text { PCR in } \\
\text { standard group }\end{array}$ & $\begin{array}{c}\text { Correlation } \\
p \text {-value }\end{array}$ \\
\hline Age & $\begin{array}{l}<50 \\
>50\end{array}$ & $\begin{array}{l}40 \% \\
20 \%\end{array}$ & $\begin{array}{l}24 \% \\
12 \%\end{array}$ & 1 \\
\hline Menopause & $\begin{array}{l}\text { Pre-menopause } \\
\text { Post-menopause }\end{array}$ & $\begin{array}{l}44 \% \\
16 \%\end{array}$ & $\begin{array}{l}24 \% \\
12 \%\end{array}$ & 0.492 \\
\hline Site of disease & $\begin{array}{l}\text { LOQ } \\
\text { Retro areolar } \\
\text { UIQ } \\
\text { UOQ } \\
\text { LIQ } \\
\text { Axilla }\end{array}$ & $\begin{array}{l}4 \% \\
28 \% \\
0 \% \\
20 \% \\
4 \% \\
4 \%\end{array}$ & $\begin{array}{l}12 \% \\
4 \% \\
4 \% \\
8 \% \\
4 \% \\
4 \%\end{array}$ & 0.575 \\
\hline Clinical staging & $\begin{array}{l}\text { IIIA } \\
\text { IIIB }\end{array}$ & $\begin{array}{l}48 \% \\
12 \%\end{array}$ & $\begin{array}{l}32 \% \\
4 \%\end{array}$ & 0.263 \\
\hline Pathology & $\begin{array}{l}\text { IDC } \\
\text { ILC } \\
\text { Mixed }\end{array}$ & $\begin{array}{l}52 \% \\
4 \% \\
4 \%\end{array}$ & $\begin{array}{l}32 \% \\
0 \% \\
4 \%\end{array}$ & 0.834 \\
\hline Comorbidities & $\begin{array}{l}\text { DM } \\
\text { HTN } \\
\text { No }\end{array}$ & $\begin{array}{l}12 \% \\
16 \% \\
40 \%\end{array}$ & $\begin{array}{l}8 \% \\
4 \% \\
28 \%\end{array}$ & 0.409 \\
\hline ER & $\begin{array}{l}+\mathrm{ve} \\
-\mathrm{ve}\end{array}$ & $\begin{array}{l}32 \% \\
28 \%\end{array}$ & $\begin{array}{l}16 \% \\
20 \%\end{array}$ & 0.004 \\
\hline PR & $\begin{array}{l}+\mathrm{ve} \\
-\mathrm{ve}\end{array}$ & $\begin{array}{l}32 \% \\
28 \%\end{array}$ & $\begin{array}{l}20 \% \\
16 \%\end{array}$ & 0.835 \\
\hline HER-2 & $\begin{array}{l}+\mathrm{ve} \\
-\mathrm{ve}\end{array}$ & $\begin{array}{l}52 \% \\
8 \%\end{array}$ & $\begin{array}{l}28 \% \\
8 \%\end{array}$ & 0.004 \\
\hline Luminal & $\begin{array}{l}\text { A } \\
\text { B-HER-2 -ve } \\
\text { B-HER-2 +ve } \\
\text { HER-2 overexpression } \\
\text { TNBC }\end{array}$ & $\begin{array}{l}0 \% \\
8 \% \\
32 \% \\
20 \% \\
0 \%\end{array}$ & $\begin{array}{l}0 \% \\
0 \% \\
20 \% \\
8 \% \\
8 \%\end{array}$ & 0.295 \\
\hline
\end{tabular}


Table (6): Non-hematologic toxicities among both groups.

\begin{tabular}{|c|c|c|c|c|c|}
\hline & \multicolumn{2}{|c|}{ Investigated group } & \multicolumn{2}{|c|}{ Standard group } & \multirow{2}{*}{$\begin{array}{c}p- \\
\text { value }\end{array}$} \\
\hline & Count & $\%$ & Count & $\%$ & \\
\hline \multicolumn{6}{|l|}{ Vomiting: } \\
\hline G1 & 18 & 72.00 & 17 & 68.00 & \multirow[t]{3}{*}{0.518} \\
\hline G2 & 6 & 24.00 & 8 & 32.00 & \\
\hline G3 & 1 & 4.00 & 0 & 0.00 & \\
\hline \multicolumn{6}{|l|}{ Diarrhea: } \\
\hline G1 & 18 & 72.00 & 20 & 80.00 & \multirow{2}{*}{1.000} \\
\hline $\mathrm{G} 2$ & 7 & 28.00 & 5 & 20.00 & \\
\hline \multirow{2}{*}{\multicolumn{6}{|c|}{$\begin{array}{l}\text { Peripheral } \\
\text { Neuropathy: }\end{array}$}} \\
\hline & & & & & \multirow{4}{*}{0.357} \\
\hline G1 & 13 & 52.00 & 9 & 36.00 & \\
\hline G2 & 8 & 32.00 & 13 & 52.00 & \\
\hline G3 & 4 & 16.00 & 3 & 12.00 & \\
\hline \multicolumn{6}{|c|}{ Table (7): Hematologic toxicities among both groups. } \\
\hline & \multicolumn{2}{|c|}{ Investigated group } & \multicolumn{2}{|c|}{ Standard group } & \multirow{2}{*}{$\begin{array}{c}p- \\
\text { value }\end{array}$} \\
\hline & Count & $\%$ & Count & $\%$ & \\
\hline \multicolumn{6}{|l|}{ Neutropenia: } \\
\hline No & 8 & 32.00 & 10 & 40.00 & \multirow[t]{4}{*}{0.923} \\
\hline G1 & 9 & 36.00 & 8 & 32.00 & \\
\hline G2 & 5 & 20.00 & 5 & 20.00 & \\
\hline G3 & 3 & 12.00 & 2 & 8.00 & \\
\hline \multicolumn{6}{|l|}{ Anemia: } \\
\hline No & 3 & 12.00 & 4 & 16.00 & \multirow[t]{3}{*}{ NA } \\
\hline Mild & 17 & 68.00 & 18 & 72.00 & \\
\hline Moderate & 5 & 20.00 & 3 & 12.00 & \\
\hline \multicolumn{6}{|l|}{$\begin{array}{l}\text { Thrombo- } \\
\text { cytopenia: }\end{array}$} \\
\hline G1 & 8 & 32.00 & 12 & 48.00 & \multirow[t]{2}{*}{0.248} \\
\hline No & 17 & 68.00 & 13 & 52.00 & \\
\hline
\end{tabular}

\section{Discussion}

Thanks to the availability of tissue biopsy before and after surgery, the introduction of metformin into neoadjuvant chemotherapy for breast cancer was an incredibly influential start for a brief period with the presence of $\mathrm{pCR}$ as a surrogate end point. In 2009, a major retrospective analysis performed by MD Anderson found that the addition of metformin to neoadjuvant chemotherapy was correlated with the addition of metformin to neoadjuvant chemotherapy in diabetic patients [24].

Multiple prospective phases II \& III trials were conducted after this. Window of opportunity trials were introduced in which metformin alone was prescribed to non-diabetic patientsfor a brief period of time, followed by a second biopsy before neoadjuvant therapy was begun. This research design enables the pure evaluation of the effect of metformin on the treatment of naive breast cancer cells
Table (8): Survival analysis.

\begin{tabular}{ccccc}
\hline & & \multicolumn{3}{c}{$p$-value } \\
\cline { 3 - 5 } & $\begin{array}{c}\text { DFS rate } \\
\text { at 2 years }\end{array}$ & $\begin{array}{c}\text { Log rank } \\
\text { test }\end{array}$ & $\begin{array}{c}\text { Breslow } \\
\text { test }\end{array}$ & $\begin{array}{c}\text { Tarone-ware } \\
\text { test }\end{array}$ \\
\hline Treatment: & & & & \\
AC/Taxol & $96.25 \%$ & 0.566 & 0.622 & 0.595 \\
AC/Taxol + & $91.25 \%$ & & & \\
Metformin & & & & \\
\hline
\end{tabular}

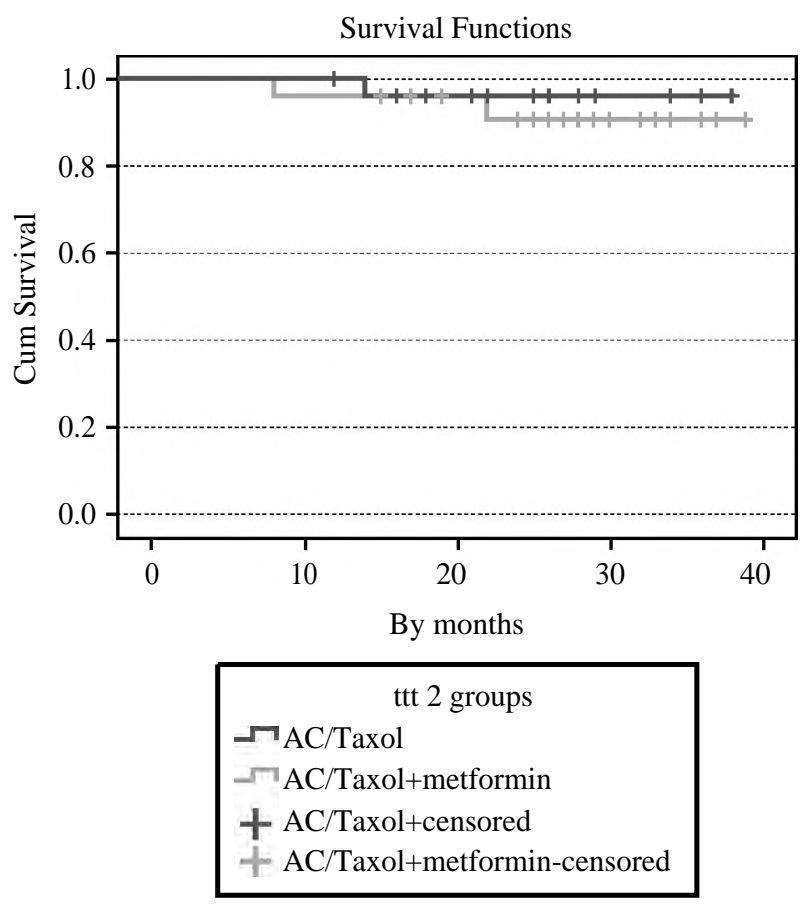

Fig. (1): Survival analysis between the two groups.

in vivo, and also more accurate assessment of suggested markers for susceptibility, and/or resistance [25-28]

After this, multiple neoadjuvant trials assessing clinical \& pathological response as end points were initiated, most of them are still recruiting [29]. A cross sectional study was conducted in Latin America, where both diabetic and non-diabetic, early, or locally advanced breast cancer patients receiving neo adjuvant chemotherapy with or without metformin were assessed. It showed statistically significant increase of pathologic complete response rate of more than 5 folds in the metformin group [30]. The METTEN study, was the first phase II prospective trial, whose results have been published in 2018, where non-diabetic HER2 +ve locally advanced treatment naïve breast cancer patients were randomized to 12 weeks of PaclitaxelTrastuzumab followed by 4 cycles FEC with vs without metformin. It showed numerically more 
pathologic complete response in the Metformin arm, and a trend toward more breast conservation surgery with tolerable comparable toxicity profiles in both arms [31]. METEOR trial, where nondiabetic hormone positive postmenopausal breast cancer patients were randomized to neoadjuvant letrozole with metformin vs placebo, showed numerical clinical response benefit with metformin, which was statistically significant in patients who showed KI $67>10 \% 4$ weeks after treatment [32]

In our randomized controlled phase II study, we tried to assess the clinical benefit of both direct (AMPK mediated) and indirect (insulin mediated) actions of metformin. That's why we included both diabetic (42\%), and non-diabetic patients (58\%), this was the approach of Alicia Van der Laata \& colleagues, where $15 \%$ of patients were diabetics [30], unlike the METTEN, and the METEOR trials, where diabetic patients were excluded $[31,32]$. In MD Anderson's retrospective study there were low possibility to have non diabetic patients who receives metformin [24]. We believe that it is better to include both as metformin showed indirect antitumor activity in non-diabetic patients in large, randomized trial NCIC CTG MA.32 [36] .

Sequential administration of anthracycline based chemotherapy, followed by Taxanes, have demonstrated the best response rates in multiple trials. In the Aberdeen trial, sequential 4 cycles of CVAP (cyclophosphamide, vincristine, doxorubicin, \& prednisolone) followed by 4 cycles of docetaxel, showed a clinical response rate (CRR) of 94\%, and PCR of 34\% [37]. The National Surgical Adjuvant Breast and Bowel Project (NSABP) protocol B-27 has shown similar results with 4 cycles of AC, followed by 4 cycles of neo-adjuvant docetaxel, with CRR of $91 \%$, clinical complete response (CCR) of 63\%, and PCR of $26 \%$ [38].

On the light of these neo adjuvant trials, together with findings of the randomized trial conducted by Sparano JA \& his Collogues, which announced weekly paclitaxel for 12 weeks as the best schedule for Taxanes following AC in the adjuvant settings [39], we used 4 AC followed by 12 taxol weekly as our chemotherapy regimen. Our control results were very close to these data, where clinical response rate was $100 \%$ vs $94 \%$ in the Aberdeen, $\&$ $91 \%$ in the NSABP B-27, CRR: $60 \%$ vs $63 \%$ in the NSABP B-27, while pCR was $36 \%$ vs $34 \%$ $\& 26 \%$ in the Aberdeen and NSABP B-27 repectively $[37,38]$.

This very good response in our study wasn't translated to more conservative surgery, where
$92 \%$ of our control group underwent MRM, which is very high in comparison to the METTEN, and NSABP B-18 trials where MRM rate was $58.6 \%$, and $68 \%$ respectively $[31,40]$. This can be attributed to advanced stage of our patients at presentation (most of them were T3, $4 \mathrm{N1}, 2$ ), or may be attributed to patients' preference at Upper Egypt.

The addition of metformin to standard neoadjuvant chemotherapy in our study resulted in numerically better complete clinical response rate, and increase of conservative surgery by 3 folds, but all without any statistical significance.

As regard the primary end point; our study showed a trend toward higher rate of pathological complete response with the addition of metformin to standard neo adjuvant chemotherapy $60 \%$ vs $36 \%$. However, the $p$-value was insignificant (0.08).

On evaluating this benefit in our study subgroups, ER +ve, and HER2 +ve tumors were the most benefitted groups, where pCR was almost doubled in both groups with a significant $p$-value (ER +ve: $32 \%$ vs $16 \%, p$-value: 0.004 ; HER2 +ve: $52 \%$ vs $28 \%, p$-value: 0.004$)$.

According to this subgroup analysis, we recommend to further study the effect of adding metformin to standard neoadjuvant chemotherapy in ER and/or HER2 +ve breast cancer patients.

\section{References}

1- BRAY F., FERLAY J., SOERJOMATARAM I., SIEGEL R.L., TORRE L.A. and JEMAL A.: Global cancer statistics 2018: GLOBOCAN estimates of incidence and mortality worldwide for 36 cancers in 185 countries. CA Cancer J. Clin., 68: 394-424, 2018.

2- IBRAHIM A.S., KHALED H.M., MIKHAIL N.N., BARAKA H. and KAMEL H.: Cancer incidence in egypt: Results of the national population-based cancer registry program. J. Cancer Epidemiol., 2014: 437971, 2014.

3- RASTOGI P., ANDERSON S.J., BEAR H.D., et al.: Preoperative chemotherapy: Updates of National Surgical Adjuvant Breast and Bowel Project Protocols B-18 and B-27. J. Clin. Oncol., 26: 778-85, 2008.

4- GRALOW J.R., BURSTEIN H.J., WOOD W., et al.: Preoperative therapy in invasive breast cancer: Pathologic assessment and systemic therapy issues in operable disease. J. Clin. Oncol., 26: 814-9, 2008.

5- KILLELEA B.K., YANG V.Q., MOUGALIAN S., et al.: Neoadjuvant chemotherapy for breast cancer increases the rate of breast conservation: Results from the National Cancer Database. J. Am. Coll. Surg., 220: 1063-9, 2015.

6- LIEDTKE C., MAZOUNI C., HESS K.R., et al.: Response to neoadjuvant therapy and long-term survival in patients with triple-negative breast cancer. J. Clin. Oncol., 26: 1275-81, 2008 . 
7- GIANNI L., PIENKOWSKI T., IM Y.H., et al.: 5-year analysis of neoadjuvant pertuzumab and trastuzumab in patients with locally advanced, inflammatory, or earlystage HER2-positive breast cancer (NeoSphere): A multicentre, open-label, phase 2 randomised trial. Lancet Oncol., 17: 791-800, 2016.

8- CAPARICA R., LAMBERTINI M., PONDE N., FUMAGALLI D., DE AZAMBUJA E. and PICCART M.: Postneoadjuvant treatment and the management of residual disease in breast cancer: State of the art and perspectives. Ther. Adv. Med. Oncol., 11: 1758835919827714, 2019.

9- CORTAZAR P., ZHANG L., UNTCH M., et al.: Pathological complete response and long-term clinical benefit in breast cancer: the CTNeoBC pooled analysis. Lancet, 384: 164-72, 2014.

10- GRADISHAR W.J., ANDERSON B.O., ABRAHAM J., et al.: Breast Cancer, Version 3.2020, NCCN Clinical Practice Guidelines in Oncology. J. Natl. Compr. Canc. Netw, 18: 452-78, 2020.

11- INZUCCHI S.E., BERGENSTAL R.M., BUSE J.B., DIAMANT M., FERRANNINI E., NAUCK M., et al.: Management of Hyperglycemia in type 2 diabetes, 2015: a patient-centered approach: Update to a position statement of the American Diabetes Association and the European Association for the Study of diabetes. Diabetes Care Am. Diabetes Assoc., 38: 140-9, 2015.

12- SCHÄFER G. BIGUANIDES: A review of history, pharmacodynamics and therapy. Diabetes Metab., 9: 148-63, 1983.

13- FORETZ M., GUIGAS B., BERTRAND L., POLLAK M. and VIOLLET B.: Metformin: From mechanisms of action to therapies. Cell Metab. Elsevier Inc., 20: 95366, 2014.

14-EVANS J.M., DONNELLY L.A., EMSLIE-SMITH A.M., ALESSI D.R. and MORRIS A.D.: Metformin and reduced risk of cancer in diabetic patients. BMJ, 330: 1304-5, 2005.

15- WRIGHT J.L. and STANFORD J.L.: Metformin use and prostate cancer in Caucasian men: Results from a population-based case-control study. Cancer Causes Control, 20, 1617, 2009.

16- LEE M-S., HSU C-C., WAHLQVIST M.L., TSAI H-N., CHANG Y-H. and HUANG Y-C.: Type 2 diabetes increases and metformin reduces total, colorectal, liver and pancreatic cancer incidences in Taiwanese: A representative population prospective cohort study of 800,000 individuals. BMC Cancer, 11: 20, 2011.

17- BOSCO J.L., ANTONSEN S., SORENSEN H.T., PEDERSEN L. and LASH T.L.: Metformin and incident breast cancer among diabetic women: A population-based casecontrol study in Denmark. Cancer Epidemiol. Biomarkers Prev., 20: 101-11, 2011.

18- RICO M., BAGLIONI M., BONDARENKO M., et al.: Metformin and propranolol combination prevents cancer progression andmetastasis in different breast cancer models. Oncotarget, 8: 2874, 2017.

19-XINTAROPOULOU C., WARD C., WISE A., MARSTON H., TURNBULL A. and LANGDON S.P.: A comparative analysis of inhibitors of theglycolysis pathway in breast and ovarian cancer cell line models. Oncotarget, 6: 25677, 2015.
20- CHATTERJEE S., THAKER N. and DE A.: Combined 2-deoxy glucose and metformin improves therapeutic efficacy of sodium-iodide symporter-mediated targeted radioiodine therapy in breast cancer cells. Breast Cancer, 7: 251, 2015.

21- DOWLING R.J., NIRAULA S., STAMBOLIC V. and GOODWIN P.J.: Metformin in cancer: Translational challenges. J. Mol. Endocrinol., 48: R31-43, 2012.

22- POLLAK M.: Insulin and insulin-like growth factor signalling in neoplasia. Nat. Rev. Cancer, 8: 915-28, 2008

23- QUEIROZ E.A., PUUKILA S., EICHLER R., et al.: Metformin induces apoptosis and cell cycle arrest mediated by oxidative stress, AMPK and FOXO3a in MCF-7 breast cancer cells. PLoS One, 9: e98207, 2014.

24- JIRALERSPONG S., PALLA S.L., GIORDANO S.H., et al.: Metformin and pathologic complete responses to neoadjuvant chemotherapy in diabetic patients with breast cancer. J. Clin. Oncol., 27: 3297-302, 2009.

25- SIMON R. LORD, NEEL PATEL, DAN LIU, JOHN FENWICK, FERGUS GLEESON, FRANCESCA BUFFA and ADRIAN L. HARRIS: Neoadjuvant Window Studies of Metformin and Biomarker Development for Drugs Targeting Cancer Metabolism. JNCI Monographs, 51: 81-86, 2015.

26- BONANNI B., PUNTONI M., CAZZANIGA M., et al. Dual effect of metformin on breast cancer proliferation in a randomized presurgical trial. J. Clin. Oncol., 30 (21): 2593-2600, 2012.

27- CAZZANIGA M., DECENSI A. and PRUNERI G.: Effect of metformin on apoptosis in a presurgical trial in nondiabetic patients with breast cancer. Cancer Res., 72 (24 Suppl): 116s, 2012.

28- HADAD S., IWAMOTO T., JORDAN L., et al.: Evidence for biological effects of metformin in operable breast cancer: A pre-operative, window-of-opportunity, randomized trial. Breast Cancer Res. Treat., 128 (3): 783-794, 2011.

29- https://clinicaltrials.gov/ct $2 /$ results?cond=Breast + Can cer\&term $=\&$ type $=$ Intr\&rslt $=\&$ age $\_v=\& g n d r=\& i n t r=M e$ tformin $\&$ titles $=$ neoadjuvant $\&$ outc $=\&$ spons $=\& l e a d=$ $\& \mathrm{id}=\&$ cntry $=\&$ state $=\&$ city $=\&$ dist $=\&$ locn $=\&$ phase $=1 \&$ phase $=2 \&$ rsub $=\&$ strd_s $=\&$ strd_e $=\& p r c d \_s=\& p r c d \_e=$ \&sfpd_s $=\& s f p d \_e=\& r f p d \_s=\& r f p d \_e=\& l u p d \_s=\& l u p d$ _e=\&sort=accessed 6/2020.

30- VAN DER LAAT A., RAMOS-ESQUIVEL A. and LANDAVERDE D.U.: 2018. Neoadjuvant Metformin Added to Systemic Therapy Increases Pathological Complete Response in Breast Cancer: A Cross-sectional Study, Mexico Hospital, Costa Rica. Archives of Breast Cancer. 5, 1 (Mar.): 32-37. DOI:https://doi.org/10.19187/abc 20185132-37, 2018.

31- MARTIN-CASTILLO B., PERNAS S., DORCA J., et al.: A phase 2 trial of neoadjuvant metformin in combination with trastuzumab and chemotherapy in women with early HER2-positive breast cancer: The METTEN study. Oncotarget, 9: 35687-704, 2018.

32- KIM J., HAN W., KIM E., JUN Y., KIM H., CHAE S., LEE E., et al.: Phase II randomized study of neoadjuvant metformin plus letrozole versus placebo plus letrozole for ER-positive postmenopausal breast cancer [METEOR study]. J. Clin. Oncol., (576) 37: 15, 2019. 
33- MiLlER A.B., HOOGSTRATEN B., STAQUET M., et al.: Reporting results of cancer treatment. Cancer, 47: 207-214, 1981.

34- LOHRISCH C.: BC Cancer Protocol Summary for Neoadjuvant or Adjuvant therapy for Early Breast Cancer Using DOXOrubicin and Cyclophosphamide Followed by Weekly PACLitaxel. BC Cancer Protocol Summary BRAJACTW. http://www.bccancer.bc.ca/chemotherapyprotocols-site/Documents/Breast/BRAJACTW Protocol.pdf

35- PROWELL T.: Food and Drug Administration. Draft guidance for Industry. Pathologic complete response in neoadjuvant treatment of high-risk early-stage breast cancer: use as an endpoint to support accelerated approval. http://www.fda.gov/downloads/Drugs /GuidanceComplianceRegulatoryInformation/Guidances/UCM305501. pdf\#search='FDA?draft?guidance?neoadjuvant'.

36- GOODWIN P.J., PARULEKAR W.R., GELMON K.A., et al.: Effect of metformin vs placebo on and metabolic factors in NCIC CTG MA.32. J. Natl. Cancer Inst., 107, 2015.
37- S.D. HEYS, A.W. HUTCHEON, T.K. SARKAR, K.N. OGSTON, I.D. MILLER, S. PAYNE, et al.: Neoadjuvant docetaxel in breast cancer: 3-year survival results from the Aberdeen trial, Clin. Breast Cancer, 3: S69-S74, 2002.

38- H.D. BEAR, S. ANDERSON, R.E. SMITH, C.E. GEYER JR., E.P. MAMOUNAS, B. FISHER, et al.: Sequential preoperative or postoperative docetaxel added to preoperative doxorubicin plus cyclophosphamide for operable breast cancer: National Surgical Adjuvant Breast and Bowel project protocol B-27, J. Clin. Oncol., 24: 20192027, 2006

39- SPARANO J.A., WANG M., MARTINO S., et al.: Weekly paclitaxel in the adjuvant treatment of breast cancer. $\mathrm{N}$. Engl. J. Med., 358: 1663-71, 2008

40- RASTOGI P., ANDERSON S.J., BEAR H.D., et al.: Preoperative Chemotherapy: Updates of National Surgical Adjuvant Breast and Bowel Project Protocols B-18 and B-27. Journal of Clinical Oncology, 26: 778-85, 2008.
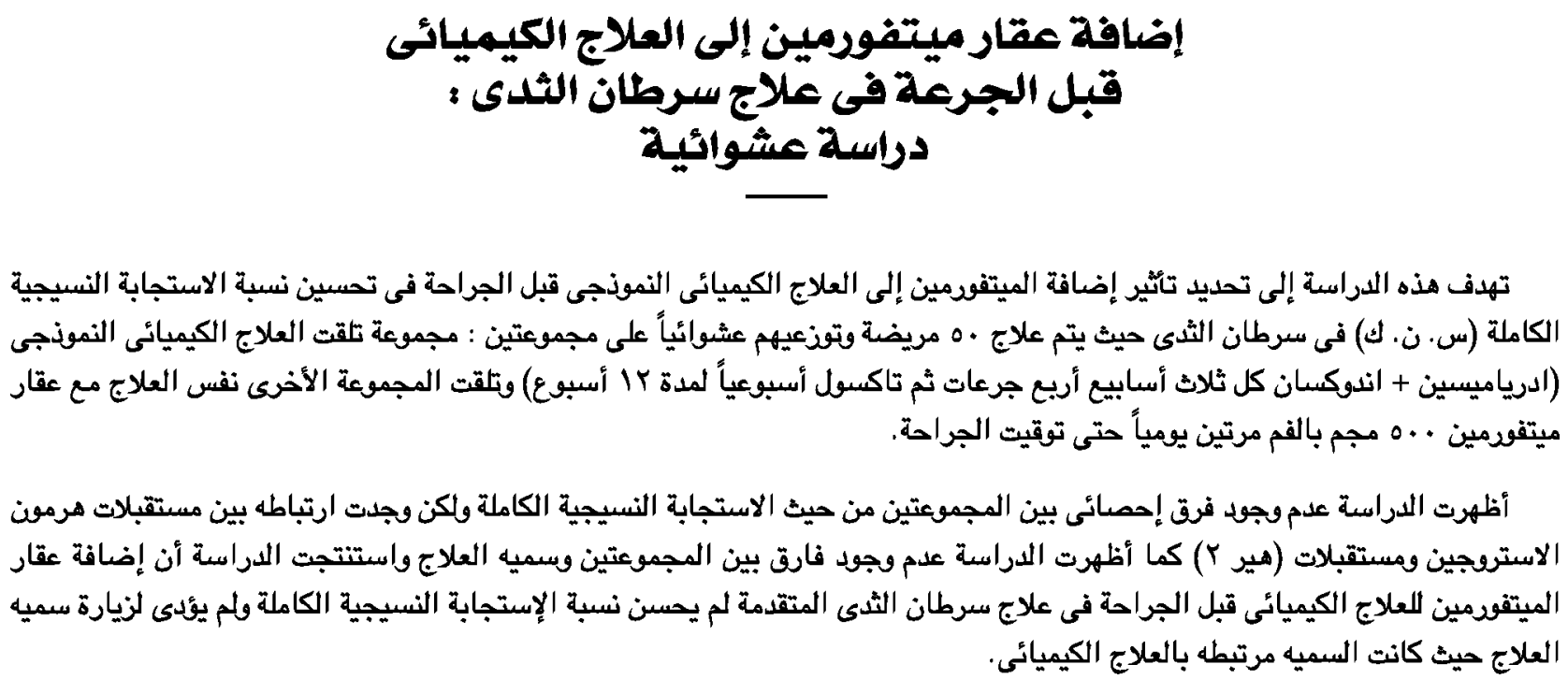